\title{
Effects of Temperature and Position Change on Neonatal Brain Regional Oxygen Saturation in Tub Bathing: A Prospective Study
}

\author{
Tomohiko Nishino (D) - Naoki Ito (D) - Shinya Tomori · \\ Satoshi Shimada (D) - Misaki Kodera (D) - Kiyoko Morita (D) • \\ Kazuhiro Takahashi · Masakazu Mimaki (D)
}

Received: May 15, 2021 / Accepted: June 29, 2021 / Published online: July 14, 2021

(C) The Author(s) 2021

\begin{abstract}
Introduction: A major goal in neonatal medicine is to reduce stress as much as possible in routine care. Bathing is one of the important routine cares for neonates, but it makes a big environmental change for them. We aimed to examine whether water temperature, room temperature, and position changes in tub bathing serve as noxious stimuli to neonates.

Methods: This prospective trial was performed in full-term and non-low-birth-weight neonates admitted to the hospital between July 2020 and March 2021. Those with underlying diseases, fetal distress, infection, and other medical conditions were excluded. Measurements were taken during the neonates' first tub bath since birth, which was performed by a trained nurse.
\end{abstract}

T. Nishino $(\varangle) \cdot$ N. Ito $\cdot$ S. Tomori $\cdot$ S. Shimada

M. Kodera - K. Morita - K. Takahashi - M. Mimaki Department of Pediatrics, Teikyo University School of Medicine, 2-11-1, Kaga, Itabashi-ku, Tokyo 1738605, Japan

e-mail: sinonosino@yahoo.co.jp

N. Ito

e-mail: ito-n@med.teikyo-u.ac.jp

S. Tomori

e-mail: stomori-teikyo@med.teikyo-u.ac.jp

S. Shimada

e-mail: satoshilions13@med.teikyo-u.ac.jp
Changes in regional oxygen saturation $\left(\mathrm{rSO}_{2}\right)$, determined using near-infrared spectroscopy, and water and room temperature, were examined at five different time points: upon entering the bath, head washing, position change, exiting the bath, and during the $3 \mathrm{~min}$ after bathing.

Results: In total, 17 neonates were analyzed. No changes in $\mathrm{rSO}_{2}$ due to head washing or position change were observed; however, $\mathrm{rSO}_{2}$ significantly decreased upon entering $(78.5 \pm 4.1 \%$ vs. $75.7 \pm 4.1 \%, p<0.001)$ and exiting the bath $(75.8 \pm 5.7 \%$ vs. $74.4 \pm 5.4 \%$, $p<0.04)$. The rate change in $\mathrm{rSO}_{2}$ upon entering the bath showed a significant inverse correlation with water temperature $(r=-0.53$, $p<0.03)$, and there were no significant correlations between $\mathrm{rSO}_{2}$ and water or room temperature upon exiting the bath. There was no change in body skin temperature before and

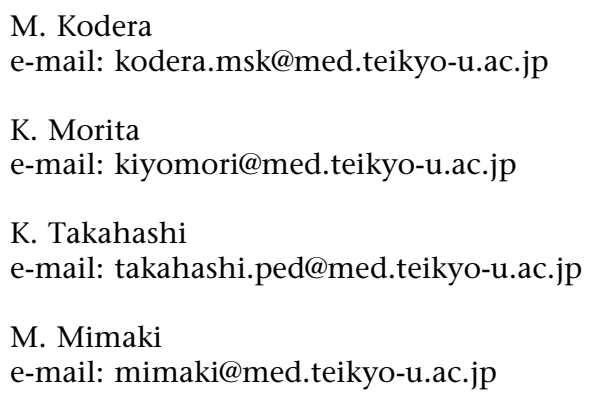


after bathing, but $\mathrm{rSO}_{2}$ gradually decreased during the 3 min after bathing.

Conclusions: Neonates may perceive certain temperatures during bathing as noxious stimuli. Therefore, methods to minimize stress associated with bathing should be implemented to reduce the difference between water temperature and room temperature during bathing.

Trial registration: This trial has been registered at UMIN repository with the trial number UMIN000041045 (https://upload.umin.ac.jp/ cgi-open-bin/ctr_e/ctr_view.cgi?recptno=R0000 46500). The date of the final dataset was April 01, 2021.

Keywords: Bathing;

Near-infrared spectroscopy; Neonatal intensive care unit; Noxious stimulus; Pediatric; Regional oxygen saturation; Room temperature; Routine care; Water temperature

\section{Key Summary Points}

\section{Why carry out this study?}

Noxious stimuli, such as pain in the neonatal period, are associated with poor neurodevelopmental prognosis.

Whether stimulation during bathing, a routine care procedure performed not only in medical settings but also at home, is also a noxious stimulus is unclear.

This trial examined whether stimuli received from water temperature, room temperature, and position changes might be perceived as noxious.

\section{What was learned from the study?}

The regional oxygen saturation decreased significantly upon entering and exiting the bath, along with change in environmental temperature, as well as for during the 3 min after bathing when no change in the body temperature was observed.
Reducing stress during bathing may be possible by bringing the water and room temperatures closer to the body temperature, with the goal of achieving an ideal bathing experience for the neonate.

\section{INTRODUCTION}

Reducing noxious stimuli in neonates during routine care remains a major goal in neonatal medicine. Medical advances have focused attention on neurodevelopment in addition to lifesaving measures. Bathing is a one of the routine cares and an important component of neonatal care because, in addition to maintaining hygiene, it contributes to the formation of parental attachment $[1,2]$. Neonates experience stress, even from diaper changes [3]. In preterm neonates, repeated noxious stimuli have been shown to reduce brain volume, adversely affect development, and decrease the thresholds of warmth and pain perception [3-6]. However, even full-term neonates present with susceptibility to neurodevelopmental abnormalities that persist beyond infancy due to repeated pain experiences [7]. Therefore, neonatal intensive care units (NICU) are managed with great care in terms of lighting, noise levels, and temperature [8, 9]. However, even though infants vary in their stress response depending on the bathing procedure [10], the bathing procedure is not standardized; hence, there is no consensus regarding the water temperature or procedures to be performed during bathing. Therefore, the stress experienced by neonates associated with bathing should be assessed. Most of the neonatal stress-assessment tools that have been developed to date rely on subjective evaluation [11], and do not always agree with brain activity recorded by electroencephalography [12]; thus, objective assessment methods are warranted. Near-infrared spectroscopy (NIRS) can be used to measure pulsatile-independent total oxygen saturation of arterial, venous, and capillary 
blood; therefore, tissue oxygen consumption can be continuously observed by monitoring regional oxygen saturation $\left(\mathrm{rSO}_{2}\right)[13,14]$. Significant changes in NIRS were observed during heel blood sampling, but not during von Frey hair stimulation of the plantar surface of the foot in neonates [15]. In other words, changes in NIRS are caused only by noxious stimuli and not by all stimuli. The experience of pain has been shown to increase oxygen consumption, with the changes occurring in the primary somatosensory cortex on the surface of the brain $[16,17]$. NIRS is thus an excellent tool for observing these changes $[15,18,19]$, which can be used to enhance the quality of routine care and reduce neonatal stress [20-24]. Because routine care is repeated daily, its optimization is important to reduce stress in neonates, which should contribute to improved neurodevelopment. This trial examined whether the stimulus caused by bathing as part of routine neonatal care was affected by temperature and position change using NIRS.

\section{METHODS}

\section{Study Population}

This prospective trial on cerebral blood flow measurement during bathing in neonates (UMIN000041045) was a quasi-experimental all-case survey conducted during the first bath after birth in a population of term neonates with a birth weight of $\geq 2500 \mathrm{~g}$ admitted to a level III NICU in Tokyo, Japan, between July 15, 2020, and March 31, 2021. Neonates whose conditions were generally stable were included in the trial; the first bath was included in the trial, the timing of which was normal for neonates. The final decision to initiate bathing was made by the attending physician.

\section{Measurement Method}

A digital device capable of measuring room temperature, water temperature, and room humidity simultaneously was installed at a distance from the bathtub, with the terminal of the water temperature meter fixed to the lower side of the bathtub. The $\mathrm{rSO}_{2}$ was measured using an INVOS 5100 NIRS cerebral oximeter (Covidien Somanetics, Troy, MI, USA). The neonate was placed on a table before bathing. Body skin temperature was measured at the axilla, and the NIRS probe was applied to the mid-forehead to begin measuring cerebral tissue oxygenation. The neonate was allowed to rest for at least $3 \mathrm{~min}$ before and after bathing. At this point, non-nutritive-sucking and tucking position was facilitated with the aim of reducing the infant's stress as needed [25], but no cuddling or other activity that would change the position of the child was performed. Bathing was started after confirming that $\mathrm{rSO}_{2}$ was stable. The probe was attached to the same site until the end of the measurement period. After bathing, the neonate's entire body was toweldried on the table to maintain warmth, and care was taken to avoid hypothermia.

\section{Bathing Method}

The neonates were bathed by one of six welltrained nurses, all of whom had been working in the NICU for more than 8 years. Prior to the start of the trial, the written instructions of the trial protocol were distributed to all nurses, who reviewed the instructions together to ensure technical uniformity in following the bathing method. The timing of bathing was standardized to approximately $90-120 \mathrm{~min}$ after oral feeding. A two-stage bathtub was filled with warm water, and the appropriate water temperature was determined by feel by the nurse in charge, who was blinded to the temperature reading. During the trial, warm water was kept flowing into the bathtub to maintain a constant water temperature. The positioning of the neonate during bathing and the order of washing were performed according to the bathing procedure implemented at our hospital (Table 1). The nurses attempted to prevent the neonates from crying. The protocol for the timing of bathing and position change was used as a rough guide, and bathing was performed in accordance with the neonate's crying and body movement. If the neonate was crying prior to 
Table 1 Bathing procedure and measurement method

\begin{tabular}{|c|c|c|c|}
\hline Time & Position & $\begin{array}{l}\text { Measurement and } \\
\text { intervention }\end{array}$ & $\begin{array}{l}\text { Analysis of } \\
\text { this trial }\end{array}$ \\
\hline & $\begin{array}{l}\text { Supine } \\
\text { position }\end{array}$ & $\begin{array}{c}\text { Body temperature } \\
\text { measurement }\end{array}$ & \\
\hline \multirow[t]{2}{*}{$3 \mathrm{~min}$} & & Rest & \\
\hline & & Start of bathing & $(\mathrm{A})$ \\
\hline $30 s$ & & Wiping the face & \\
\hline $30 \mathrm{~s}$ & & Head washing & (B) \\
\hline $60 s$ & & $\begin{array}{l}\text { Washing the trunk } \\
\text { and limbs }\end{array}$ & \\
\hline Position & change & & (C) \\
\hline $60 s$ & $\begin{array}{l}\text { Prone } \\
\text { position }\end{array}$ & $\begin{array}{l}\text { Washing the buttocks } \\
\text { and back }\end{array}$ & \\
\hline \multicolumn{4}{|c|}{ Position change } \\
\hline \multirow[t]{2}{*}{$30 s$} & $\begin{array}{l}\text { Supine } \\
\text { position }\end{array}$ & $\begin{array}{l}\text { Washing the inguinal } \\
\text { region }\end{array}$ & \\
\hline & & Exiting the bath & (D) \\
\hline \multirow[t]{2}{*}{$3 \mathrm{~min}$} & & $\begin{array}{l}\text { Dressing and heat } \\
\text { retention to rest }\end{array}$ & $(\mathrm{E})$ \\
\hline & & $\begin{array}{l}\text { Body temperature } \\
\text { measurement }\end{array}$ & \\
\hline
\end{tabular}

any of the four moments used for analysis(A) upon entering the bath, (B) head washing, (C) position change, and (D) exiting the bathwe waited until they had stopped crying before continuing.

\section{Exclusion Criteria}

As this trial was performed to evaluate routine care, neonates with as close to normal medical circumstances as possible were selected. The exclusion criteria were as follows: those undergoing warming or humidification in an incubator and treatment including intravenous fluid therapy or phototherapy; those with fetal distress, postoperative bleeding, or abnormal coagulation parameters; respiratory or heart failure requiring oxygen administration; gastrointestinal symptoms; malformations including congenital heart disease; and suspected chromosomal/genetic abnormalities. Neonates whose mothers were administered antipsychotics or thyroid hormones during birth were also excluded. The data of patients who started treatment after the bathing measurements were excluded from the analysis.

\section{Statistical Analysis}

All statistical analyses were performed using $\mathrm{R}$ version 3.6.1 ( $\mathrm{R}$ Foundation for Statistical Computing, Vienna, Austria). The measurements that were taken at five time points, at the aforementioned moments of (A), (B), (C), and (D) and a period of time (E) during the $3 \mathrm{~min}$ after bathing, were evaluated (Table 1). At (A), (B), (C) and (D): the $\mathrm{rSO}_{2}$ before (mean of $-3-0 \mathrm{~s}$ before intervention) and after the intervention (mean of 6-9 s after the intervention) were compared using a paired $t$ test. Pearson's correlation analysis was performed to determine the correlation between the rate change in $\mathrm{rSO}_{2}$ and water or room temperature. The body skin temperatures before and after bathing were compared using a paired $t$ test. Rate changes in $\mathrm{rSO}_{2}$ during the $3 \mathrm{~min}$ after bathing were calculated by setting $\mathrm{rSO}_{2}$ before (mean of -3-0 s before intervention) as 0 . The $t$ test results were expressed as mean \pm standard deviation. In all analyses, $p<0.05$ was considered to indicate statistical significance.

\section{Ethical Approval}

The trial was approved by the Teikyo University Ethical Review Board for Medical and Health Research Involving Human Subjects (protocol number 20-083). All procedures in the present trial involving human participants were performed in accordance with the ethical standards of the institutional and/or national research committee and with the 1964 Declaration of Helsinki and its later amendments or comparable ethical standards. Informed consent was obtained from the day of hospitalization to the day before bathing. The parents/guardians of 


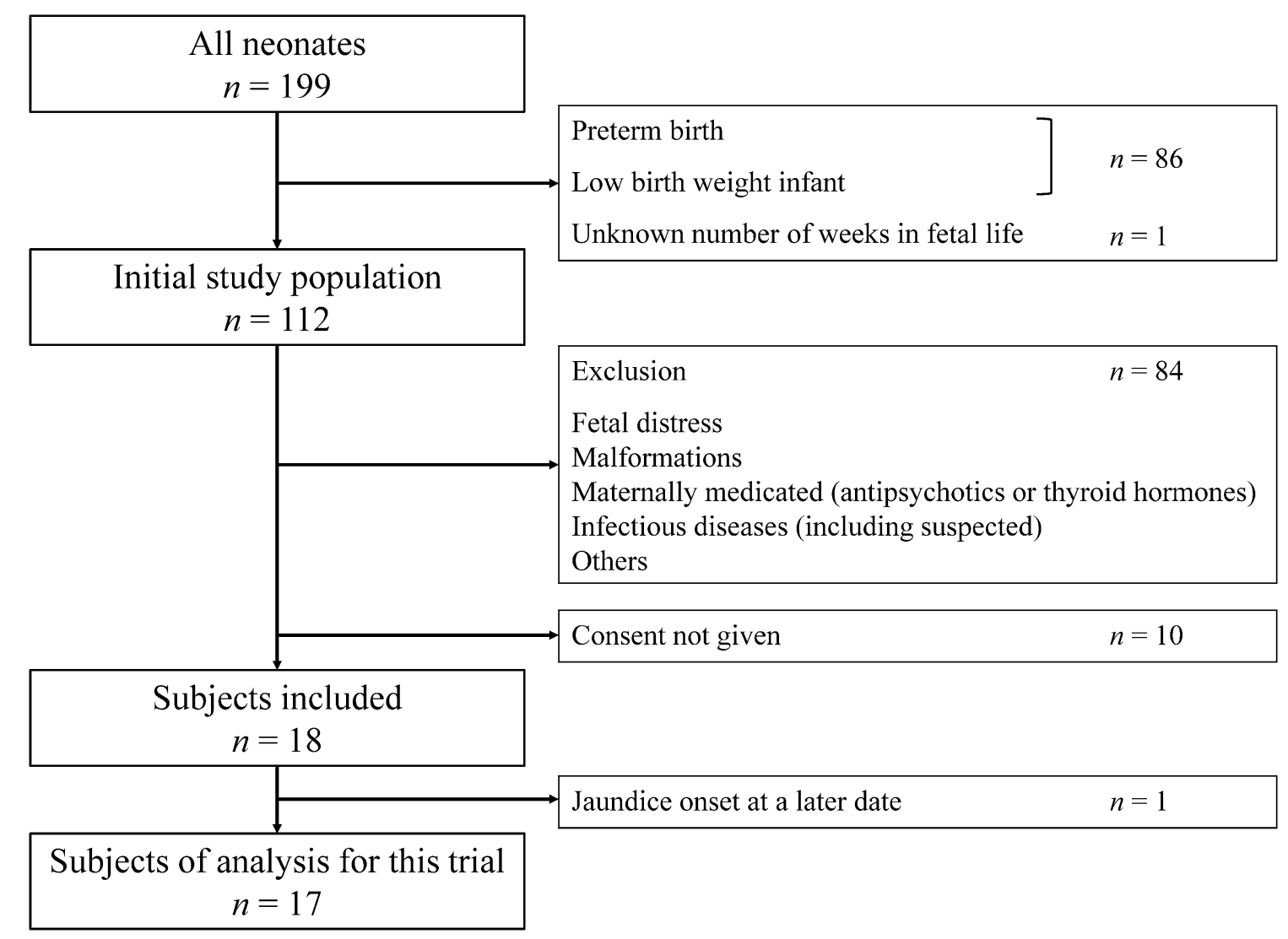

Fig. 1 Flow diagram showing the study selection procedure. Among all neonates admitted to the neonatal intensive care unit during the trial period, 87 were born at full-term and did not have low birth weights.

the neonates were provided a written and verbal explanation of the procedures in plain language, and written consent was obtained for participation in the research and the publication of the results. Additionally, explained the right to refuse participation and withdraw consent at will were also explained.

\section{Trial Registration}

NSBB study has been registered at UMIN repository with the trial number UMIN000041045 (https://upload.umin.ac.jp/ cgi-open-bin/ctr_e/ctr_view.cgi?recptno=R0000 46500). The date of the final data set was April 01, 2021.
Measurements were performed in 18 neonates who met the inclusion criteria. One neonate was later excluded from the analysis due to the development of jaundice

\section{RESULTS}

Of the 199 neonates admitted to the NICU during the trial period, 112 met the initial inclusion criteria (Fig. 1). Among these 112 neonates, 84 met the inclusion and exclusion criteria (Table 2), and the trial sample size thus comprised 28 neonates. Measurements were taken for 18 neonates for whom parental consent was obtained, but one patient developed jaundice the day after the completion of measurements and was excluded from the trial. The characteristics and bathing environments of the 17 neonates included in the final analyses are shown in Tables 3 and 4, respectively. The median time from last oral feeding to bathing was $105 \mathrm{~min}$ (interquartile range $99-110 \mathrm{~min}$ ). The trend of $\mathrm{rSO}_{2}$ from $3 \mathrm{~s}$ before to $9 \mathrm{~s}$ after each intervention is shown in Fig. 2. Significant 
Table 2 Details of the patients who met the exclusion criteria

\begin{tabular}{ll}
\hline Exclusion criteria & $\boldsymbol{n}$ \\
\hline Having already been bathed & 25 \\
Fetal distress & 15 \\
Maternal medication & 15 \\
Intrauterine infections (including suspected) & 3 \\
Toxoplasmosis & 2 \\
Hepatitis B & 1 \\
Varicella & 1 \\
Coronavirus disease 2019 & 1 \\
Unknown & 1 \\
Neonatal infections (including suspected) & 5 \\
Neonatal toxic shock-like exanthematous disease & 1 \\
Unknown & 1 \\
Congenital malformations & 1 \\
Ventricular septal defect & 1 \\
Hydronephrosis & 1 \\
Twin-to-twin transfusion syndrome & 1 \\
Esophageal atresia & 1 \\
Cerebral dysplasia & 1 \\
Natal tooth & 1 \\
Meconium aspiration syndrome & 1 \\
Peripartum trauma & 1 \\
Bradycardia & 1 \\
Arrhythmia & 1 \\
Respiratory distress syndrome & 1 \\
High serum creatine kinase level & 1 \\
\hline
\end{tabular}

decreases in $\mathrm{rSO}_{2}$ from before the intervention were observed upon entering (Fig. 3A, $78.5 \pm 4.1 \%$ vs. $75.7 \pm 4.1 \%, p<0.001)$ and exiting the bath (Fig. 3B, $75.8 \pm 5.7 \%$ vs. $74.4 \pm 5.4 \%, p<0.04)$. However, no variations
Table 3 Patient characteristics

\begin{tabular}{ll}
\hline & $\mathbf{n = 1 7}$ \\
\hline Sex (boy/girl) & $6 / 11$ \\
Gestational age at birth (weeks) & $38.6 \pm 1.4$ \\
Birth weight (g) & $3094 \pm 376$ \\
Apgar score at 1 min (quartile range) & $8(8-8)$ \\
Apgar score at 5 min (quartile range) & $9(9-9)$ \\
Disease and reason for hospitalization: & \\
Infant of diabetic mother & 12 \\
Transient tachypnea & 2 \\
Transient apnea & 2 \\
Hypoglycemia & 1 \\
\hline
\end{tabular}

were detected during head washing $(75.6 \pm 4.7 \%$ vs. $75.9 \pm 5.0 \%, p=0.36)$ or position change $(74.5 \pm 5.0 \%$ vs. $74.5 \pm 5.1 \%$, $p=0.94)$. The rate change in $\mathrm{rSO}_{2}$ upon entering the bath showed a significant inverse correlation only with water temperature $(r=$ $-0.53, p<0.03$ ) (Fig. 4). There were no significant correlations between $\mathrm{rSO}_{2}$ and water or room temperature upon exiting the bath. There was no significant difference in body skin temperature before and after bathing $\left(37.0 \pm 0.26^{\circ} \mathrm{C}\right.$ vs. $\left.36.9 \pm 0.31^{\circ} \mathrm{C}, p=0.15\right)$. During the $3 \mathrm{~min}$ after bathing, $\mathrm{rSO}_{2}$ showed a gradual decrease (Fig. 5). Water temperature, room temperature, and humidity were kept constant during all measurements. No adverse events occurred during the trial.

\section{DISCUSSION}

The $\mathrm{rSO}_{2}$ significantly decreased upon entering and exiting the bath in this trial. The change in $\mathrm{rSO}_{2}$ was greater with higher water temperature upon entering the bath and was less pronounced at water temperatures closer to the body skin temperature. Bathing can bring about a variety of changes such as hemodynamic in neonates; however, the lack of a uniform change in $\mathrm{rSO}_{2}$ implies that may have been 
Table 4 Environmental characteristics and body temperature (BT) at the time of bathing

\begin{tabular}{lllllll}
\hline $\begin{array}{l}\text { Patient } \\
\text { number }\end{array}$ & $\begin{array}{l}\text { Age } \\
\text { (days) }\end{array}$ & $\begin{array}{l}\text { Room } \\
\text { temperature }\left({ }^{\circ} \mathbf{C}\right)\end{array}$ & $\begin{array}{l}\text { Humidity } \\
(\%)\end{array}$ & $\begin{array}{l}\text { Water } \\
\text { temperature }\left({ }^{\circ} \mathbf{C}\right)\end{array}$ & $\begin{array}{l}\text { BT before } \\
\text { bathing }\left({ }^{\circ} \mathbf{C}\right)\end{array}$ & $\begin{array}{l}\text { BT after bathing } \\
\left({ }^{\circ} \mathbf{C}\right)\end{array}$ \\
\hline 1 & 2 & 26.4 & 52 & 39.1 & 36.8 & 36.3 \\
2 & 3 & 25.8 & 42 & 37.5 & 37.2 & 37.0 \\
3 & 4 & 26.0 & 42 & 37.5 & 37.0 & 37.1 \\
4 & 3 & 26.8 & 39 & 37.2 & 37.3 & 37.1 \\
5 & 3 & 25.9 & 35 & 39.1 & 36.9 & 37.1 \\
6 & 4 & 24.8 & 31 & 36.4 & 37.1 & 36.9 \\
7 & 2 & 25.6 & 33 & 37.6 & 37.5 & 36.9 \\
8 & 4 & 25.4 & 37 & 38.9 & 37.3 & 36.7 \\
9 & 2 & 25.1 & 42 & 38.9 & 36.9 & 37.1 \\
10 & 3 & 24.8 & 44 & 39.9 & 36.4 & 36.9 \\
11 & 3 & 24.8 & 34 & 39.0 & 37.0 & 37.1 \\
12 & 3 & 25.1 & 34 & 39.0 & 36.8 & 36.4 \\
13 & 4 & 25.4 & 39 & 38.2 & 36.6 & 37.0 \\
14 & 3 & 25.5 & 45 & 39.5 & 37.1 & 37.7 \\
15 & 3 & 25.1 & 37 & 39.2 & 36.9 & 37.0 \\
16 & 3 & 26.2 & 50 & 37.9 & 37.0 & 36.7 \\
17 & 3 & 26.0 & 36 & 37.5 & 37.0 & 36.7 \\
\hline & & & & & & \\
\hline
\end{tabular}

affected by temperature. Additionally, $\mathrm{rSO}_{2}$ showed a uniform change upon exiting the bath at a room temperature of approximately $25^{\circ} \mathrm{C}$. It is noteworthy that environmental temperature would cause such a different response. Although many reports related to bathing in neonates have been published, to the best of our knowledge, this is the first trial involving the real-time measurement of cerebral oxygen saturation, and each of temperatures in neonates during bathing.

Neonates may perceive the water temperature upon entering the bath as noxious stimulation. The decrease in $\mathrm{rSO}_{2}$ upon entering the bath observed in this trial suggests that bathing was perceived as a noxious stimulus. The change in $\mathrm{rSO}_{2}$ was insignificant at approximately $37^{\circ} \mathrm{C}$ but was substantial at approximately $40^{\circ} \mathrm{C}$ and showed a significant inverse correlation with water temperature. Even if the temperature of the warm water is what a seasoned medical professional would consider appropriate for bathing, higher temperatures served as stimuli. In human somatosensory perception, temperature and pain are processed through the spinothalamic tract. Thermal stimulation at $37-40^{\circ} \mathrm{C}$, which was used in the present trial, activates mainly the C-fibers, and the magnitude of stimulation is dependent on temperature [26]. In addition, a study in rats reported that the temperature threshold for the recognition of noxious heat stimulus was low at early postnatal ages and increased over the subsequent days [27]. Therefore, even if the parent feels that the temperature is appropriate, it is important to consider the perception of water temperature by the neonate to avoid stress during bathing. 


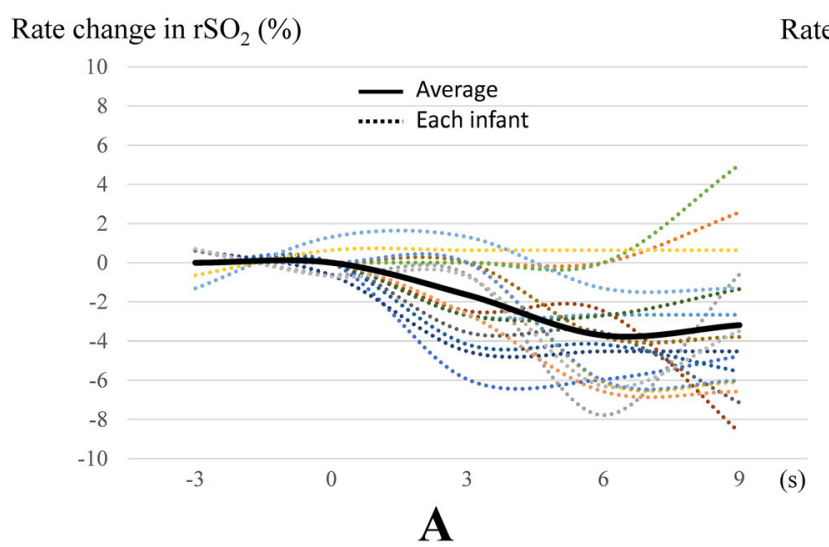

Rate change in $\mathrm{rSO}_{2}(\%)$

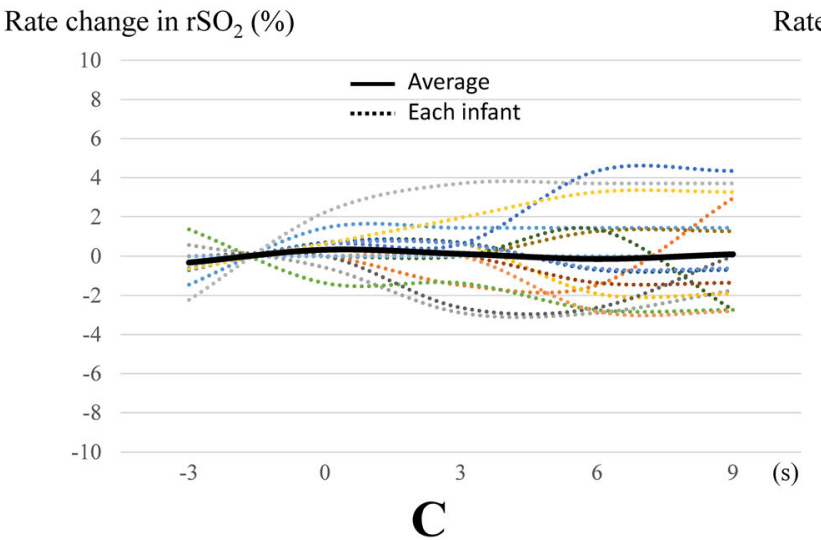

Rate change in $\mathrm{rSO}_{2}(\%)$

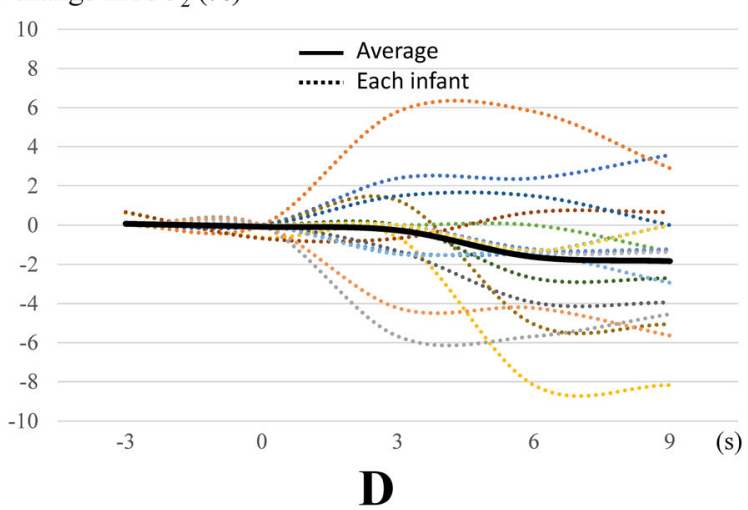

Fig. 2 Trend of rate changes in regional oxygen saturation $\left(\mathrm{rSO}_{2}\right)$ from $3 \mathrm{~s}$ before to $9 \mathrm{~s}$ after each moment of intervention. In each figure, the vertical axis represents the rate change in $\mathrm{rSO}_{2}$ and the horizontal axis represents the time from $3 \mathrm{~s}$ before to $9 \mathrm{~s}$ after the intervention. The rate change in $\mathrm{rSO}_{2}$ was set to (each $\left.\mathrm{rSO}_{2}\right) /\left(\mathrm{rSO}_{2}\right.$ before

The room temperature at the time of exiting the bath may be stressful for neonates. The decrease in $\mathrm{rSO}_{2}$ observed in this trial upon exiting the bath was uniform even at the recommended controlled room temperature of $25-27^{\circ} \mathrm{C}$. The World Health Organization recommends a warm room with a temperature not less than $25^{\circ} \mathrm{C}$ with no draft as the environment for neonatal care [8]. However, this view is a recommendation for the general environment and does not take into account the room temperature when exiting the bath. The activation of transient receptor potential melastatin 8, which is mainly involved in perception of temperatures of approximately $25^{\circ} \mathrm{C}$, is associated with insensible temperatures due to its intervention: mean of -3 to $0 \mathrm{~s}$ before treatment), and the trend of rate change in $\mathrm{rSO}_{2}$ from each $3 \mathrm{~s}$ before to $9 \mathrm{~s}$ after intervention is shown. A On entering the bath; B Head washing; C Position change; D Exiting the bath. The dotted lines show the values for each patient, and the thick solid lines show the average for all patients

analgesic properties [28]. However, as sensory processes continue to develop after birth [29], the temperature response in the neonatal period remains immature. Transient receptor potential melastatin 8 expression continues from the fetal stage to several weeks after birth [30]. This suggests that the neonates perceived room temperature as a noxious stimulus due to their immature transient receptor potential channel expression. However, it is arguable that only room temperature is responsible for the change in $\mathrm{rSO}_{2}$, as temperature perception is a complex response involving many channels [26], and the neonates included in this trial had been housed at constant room temperatures prior to bathing. The temperature set point at 


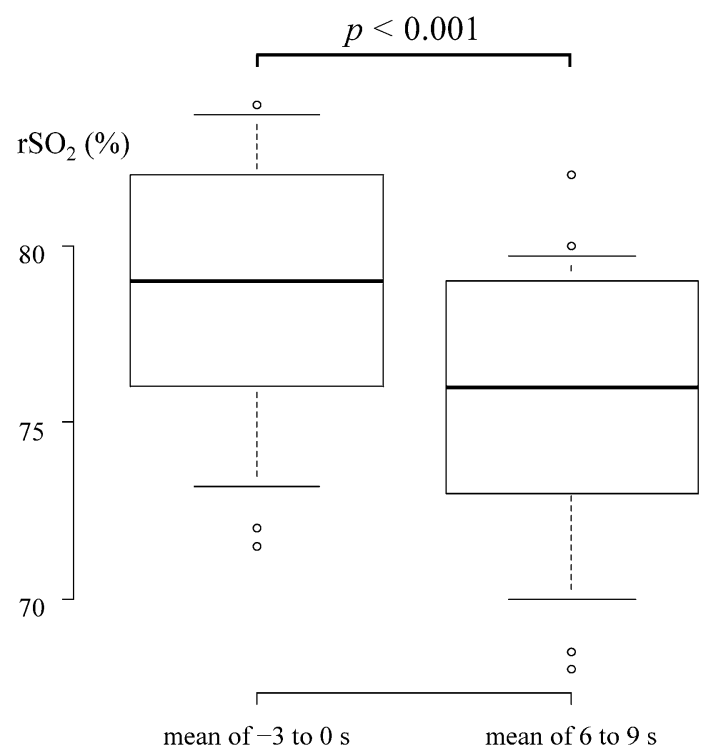

A

Fig. 3 Comparison of regional oxygen saturation $\left(\mathrm{rSO}_{2}\right)$ before and after the intervention on $\mathbf{A}$ entering the bath and $\mathbf{B}$ exiting the bath. In each panel, the vertical axis shows $\mathrm{rSO}_{2}$ values and the horizontal axis shows the $\mathrm{rSO}_{2}$

which the channel activity of thermoreceptors is induced is affected by various substances [31, 32], and some factors during the neonatal period may have caused an effect. Consideration should be given to the room temperature at the time of exiting the bath, but further investigation of this issue is required.

Temperature maintenance for neonates after bathing must be performed more carefully rather than merely evaluating the body skin temperature. In this trial, $\mathrm{rSO}_{2}$ gradually decreased during the $3 \mathrm{~min}$ after bathing. In contrast, no significant change in body skin temperature was observed. These results indicate that body skin temperature may be compensated, which indicates that the stress experienced by neonates cannot be assessed by observing body skin temperature alone. Previous reports have shown a decrease in body temperature and an increase in peripheral oxygen consumption before and after bathing in 19 neonates based on NIRS [33]. The difference in temperature between the bath water and room air contributes to heat dissipation and decreases

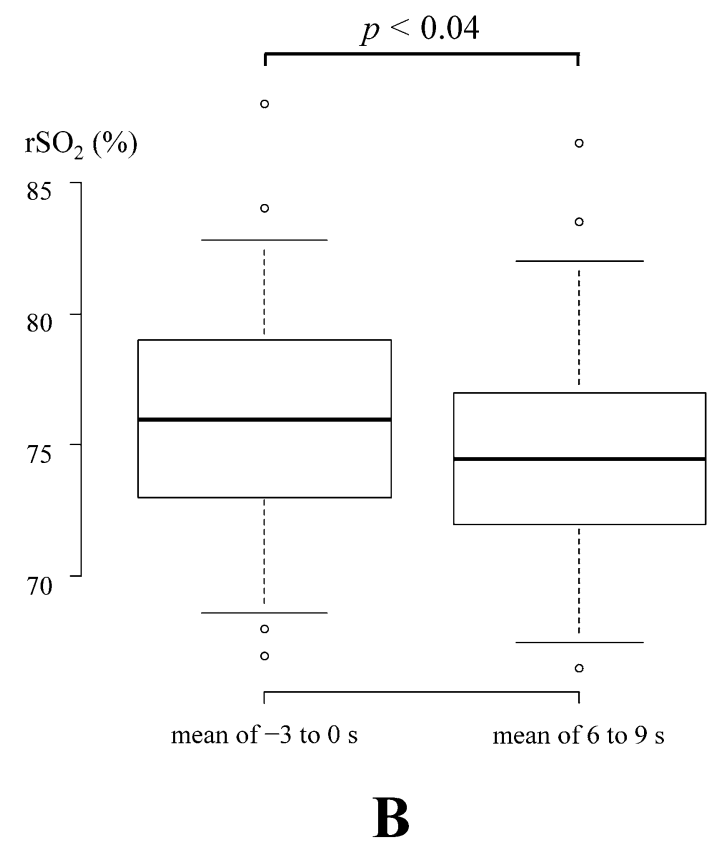

values before (mean of $-3-0 \mathrm{~s}$ before intervention) and after (mean of 6-9 s after intervention) the intervention. A paired $t$ test was used for analyses

the body skin temperature, leading to compensatory heat production by pheochromocytes [34]. Various bathing methods involving temperature maintenance have been attempted by evaluating body temperature as an indicator $[35,36]$; however, it should be noted that stress may be applied even if no change in body temperature is observed. In addition, to the best of our knowledge, previous reports have not examined room temperature after exiting the bath. Oxygen consumption in neonates is highly dependent on environmental temperature [33]. Therefore, reducing stress in neonates is possible by maintaining a higher room temperature to eliminate temperature differences upon exiting the bath.

In this trial, no changes in $\mathrm{rSO}_{2}$ associated with position change or head washing during bathing were observed, which suggests stability during tub bathing. In a previous study, the cerebral tissue oxygenation index obtained using NIRS was significantly altered by a $15^{\circ}$ head-up tilt in 17 healthy, full-term neonates 2-4 weeks after birth [37]. Thus, $\mathrm{rSO}_{2}$ 


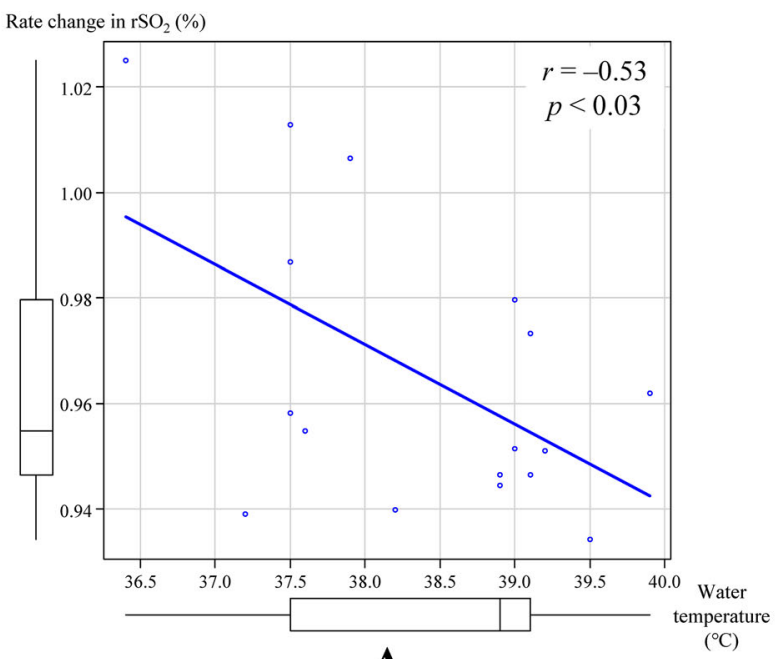

A

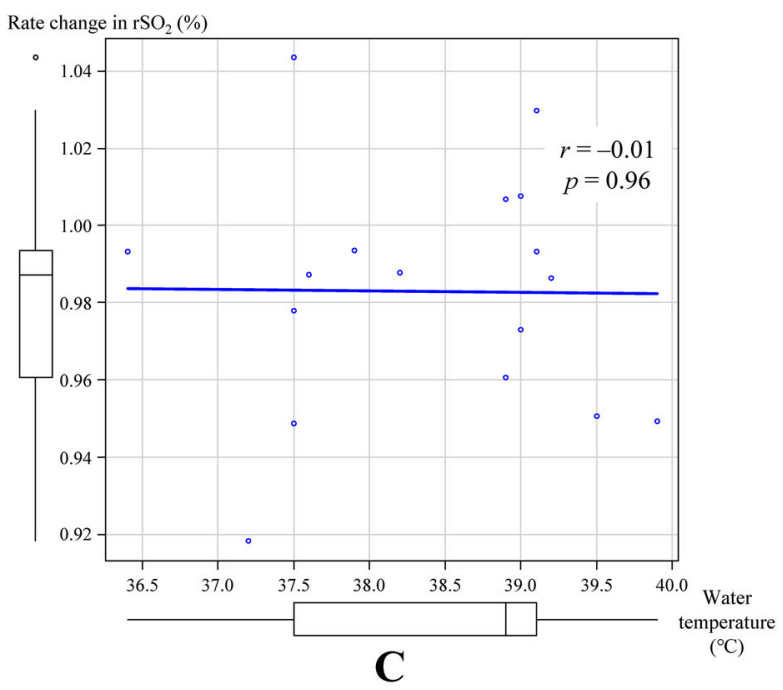

Fig. 4 Correlations between rate change in regional oxygen saturation $\left(\mathrm{rSO}_{2}\right)$ and water temperature and room temperature. In each figure, the vertical axis represents the rate change in $\mathrm{rSO}_{2}$ and the horizontal axis represents the temperature. Rate change in $\mathrm{rSO}_{2}$ was set to $\left(\mathrm{rSO}_{2}\right.$ after intervention: mean of 6-9 s after

monitoring by NIRS can also be performed to evaluate the effects of rapid repositioning on neonates. Traditional sponge bathing is known to affect hemodynamics and respiratory status and cause stress in neonates [38]. Tub bathing has recently attracted attention due to preventing the lowering of body temperature, the decrease in dryness and redness of skin after bathing, as well as improved stability compared to a sponge bath during bathing $[38,39]$. The
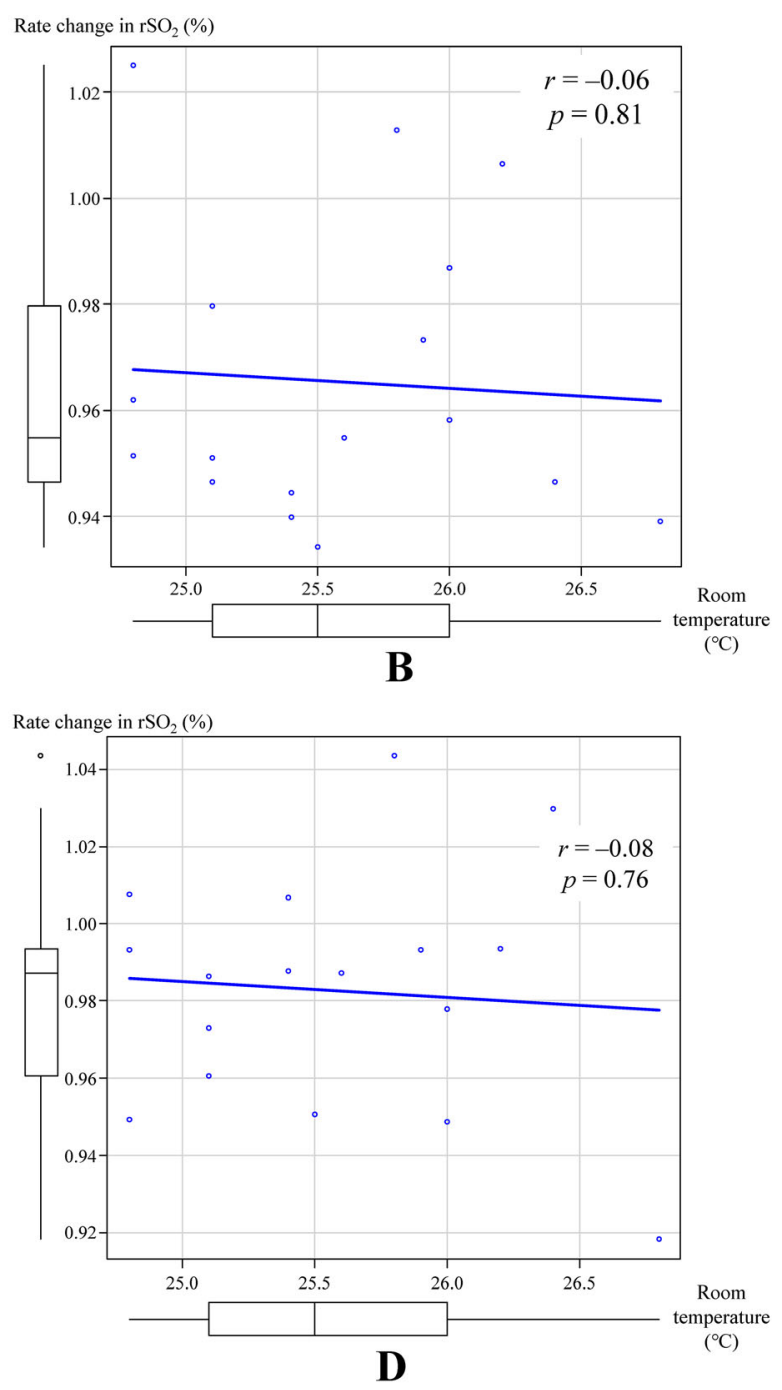

intervention $) /\left(\mathrm{rSO}_{2}\right.$ before intervention: mean of - 3-0 s before intervention). Differences between $\mathbf{A}$ on entering the bath and water temperature; $\mathbf{B}$ on entering the bath and room temperature; $\mathbf{C}$ exiting the bath and water temperature; $\mathbf{D}$ exiting the bath and room temperature

stability and safety of the procedure are important because the bathing of neonates is generally performed by families who may be unfamiliar with neonatal care.

This trial has several limitations. First, NIRS can only measure the pain response and not the pain stimulus itself. Because a time lag occurs before oxygen consumption, the pain response occurs several seconds after the stimulus is applied. The timing of this trial was chosen to 
Rate change in $\mathrm{rSO}_{2}(\%)$

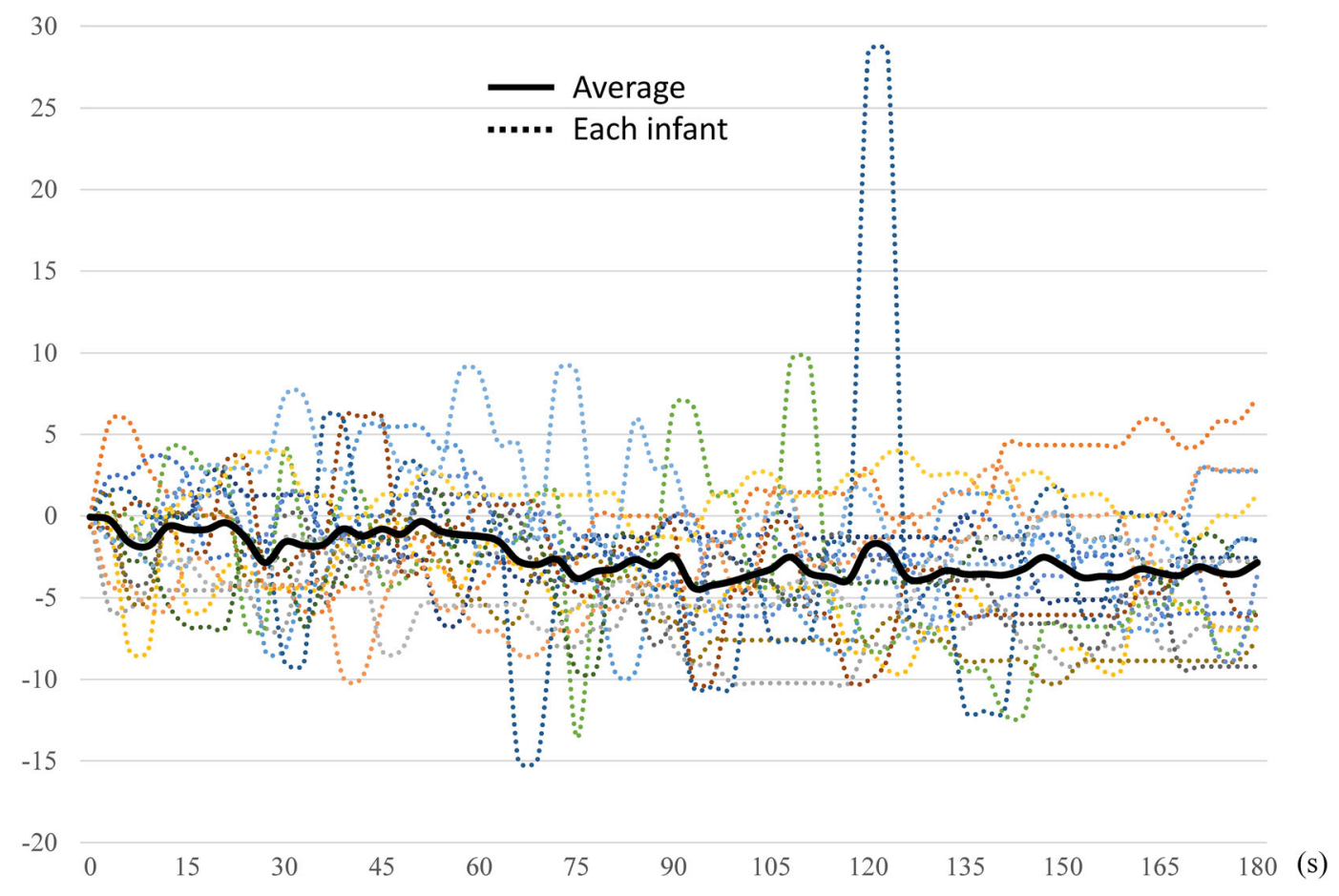

Fig. 5 Rate changes in regional oxygen saturation $\left(\mathrm{rSO}_{2}\right)$ during the $3 \mathrm{~min}$ after exiting the bath. The vertical axis represents the rate change in $\mathrm{rSO}_{2}$ and the horizontal axis represents the time during the $3 \mathrm{~min}$ after exiting the bath. Preintervention (average of $3 \mathrm{~s}$ before and moment of

be similar to a previous study [40], and it is considered to have a certain reliability. In addition, the change in $\mathrm{rSO}_{2}$ is known to vary with blood flow [14], which may be affected by factors such as water pressure or buoyancy. Interestingly, however, only a small change in $\mathrm{rSO}_{2}$ was observed upon entering the bathtub when the water temperature was close to the body temperature. This may have occurred due to the lesser influence of the aforementioned factors. As this trial was performed to evaluate routine care, the conditions were maintained as similar as possible to normal bathing. Therefore, heart rate, saturation of percutaneous oxygen, and blood pressure, all of which require the use of a measurement device, were not measured during bathing. These factors, along with respiratory rate and crying, might have affected $\mathrm{rSO}_{2}$ and should be examined in future studies. Second, the sample size was small due exiting the bath) was defined as 0 , and the trend of $\mathrm{rSO}_{2}$ during the $3 \mathrm{~min}$ after exiting the bath is shown. The dotted lines show the values for each patient, and the thick solid lines depict the average for all patients

to the small number of full-term births at a single institution. We aimed to have a normally distributed sample of 30 patients, but this was not achieved because many families did not consent to participate in the trial. One of the most common reasons for this was because parents wished to bathe their child for the first time themselves rather than allowing it to be performed by a nurse. The results of all parameters in this trial showed normality and were suitable for statistical analysis, with maintenance of a certain level of reliability. Moreover, by limiting the number of patients to a single institution, it was possible to ensure a uniform bathing method by skilled medical personnel that kept neonates in a stable condition. The stress experienced by infants during bathing due to the technique of the caregiver has been well described [41]. This problem was addressed in the present trial by standardizing the routine 
care performed. During the trial, no cases of aborted measurements due to electrode dislodgement were recorded, indicating the stability of the technique. However, $f$ urther studies including a larger study population and implementing strict temperature controls should be conducted.

\section{CONCLUSIONS}

We suggest the implementation of a water temperature close to the body temperature of neonates upon entering the bath and decreasing the temperature changes upon exiting the bath with utmost care as temperature changes can be perceived by neonates as noxious stimuli. Because bathing is necessary for hygiene and fostering parental attachment, determining the best method for minimizing stress experienced by neonates during bathing is essential.

\section{ACKNOWLEDGEMENTS}

We thank the participants of the trial.

Funding. No funding or sponsorship was received for this trial or publication of this article. The Rapid Service Fee was funded by the authors.

Editorial Assistance. The authors would like to thank Enago (www.enago.jp) for the English language review. The fee for this service was funded by the authors.

Authorship. All authors meet the International Committee of Medical Journal Editors (ICMJE) criteria for authorship for this article, take responsibility for the integrity of the work as a whole, and have given their approval for this version to be published.

Author Contributions. All authors contributed to the study conception and design. Tomohiko Nishino drafted the manuscript and prepared the figures; Tomohiko Nishino and Naoki Ito contributed to the conception and design of the study; Shinya Tomori, Satoshi
Shimada, Misaki Kodera, Kiyoko Morita and Kazuhiro Takahashi critically reviewed the manuscript; and Masakazu Mimaki supervised the whole study. All authors read and approved the final manuscript.

Disclosures. Tomohiko Nishino, Naoki Ito, Shinya Tomori, Satoshi Shimada, Misaki Kodera, Kiyoko Morita, Kazuhiro Takahashi and Masakazu Mimaki have nothing to disclose.

Compliance with Ethics Guidelines. The trial was approved by the Teikyo University Ethical Review Board for Medical and Health Research Involving Human Subjects (Protocol Number 20-083). All procedures in studies involving human participants were performed in accordance with the ethical standards of the institutional and/or national research committee and with the 1964 Declaration of Helsinki and its later amendments or comparable ethical standards. Informed consent was obtained from the day of hospitalization to the day before bathing. The parents/guardians of the neonates were provided a written and verbal explanation of the procedures in plain language, and written consent was obtained for participation in the research and the publication of the results. Additionally, explained the right to refuse participation and withdraw consent at will were also explained.

Data Availability. The datasets generated during the present study are available from the UMIN repository: https://upload.umin.ac.jp/ cgi-bin/ctr_e/ctr_view.cgi?recptno=R000046500. The date of the final dataset is April 1, 2021.

Open Access. This article is licensed under a Creative Commons Attribution-NonCommercial 4.0 International License, which permits any non-commercial use, sharing, adaptation, distribution and reproduction in any medium or format, as long as you give appropriate credit to the original author(s) and the source, provide a link to the Creative Commons licence, and indicate if changes were made. The images or other third party material in this article are included in the article's Creative Commons licence, unless indicated otherwise in a credit 
line to the material. If material is not included in the article's Creative Commons licence and your intended use is not permitted by statutory regulation or exceeds the permitted use, you will need to obtain permission directly from the copyright holder. To view a copy of this licence, visit http://creativecommons.org/licenses/by$\mathrm{nc} / 4.0 /$.

\section{REFERENCES}

1. Franck LS, Quinn D, Zahr L. Effect of less frequent bathing of preterm infants on skin flora and pathogen colonization. J Obstet Gynecol Neonatal Nurs. 2000;29(6):584-9.

2. Blume-Peytavi U, Cork MJ, Faergemann J, Szczapa J, Vanaclocha F, Gelmetti C. Bathing and cleansing in newborns from day 1 to first year of life: recommendations from a European round table meeting. J Eur Acad Dermatol Venereol. 2009;23(7):751-9.

3. Smith GC, Gutovich J, Smyser C, Pineda R, Newnham $\mathrm{C}$, Tjoeng $\mathrm{TH}$, et al. Neonatal intensive care unit stress is associated with brain development in preterm infants. Ann Neurol. 2011;70(4):541-9.

4. Anand KJ. Effects of perinatal pain and stress. Prog Brain Res. 2000;122:117-29.

5. Grunau RE, Whitfield MF, Petrie-Thomas J, Synnes AR, Cepeda IL, Keidar A, et al. Neonatal pain, parenting stress and interaction, in relation to cognitive and motor development at 8 and 18 months in preterm infants. Pain. 2009;143(1-2):138-46.

6. Vinall J, Grunau RE. Impact of repeated procedural pain-related stress in infants born very preterm. Pediatr Res. 2014;75(5):584-7.

7. Hermann C, Hohmeister J, Demirakca S, Zohsel K, Flor H. Long-term alteration of pain sensitivity in school-aged children with early pain experiences. Pain. 2006;125(3):278-85.

8. WHO. Pregnancy, Childbirth, Postpartum and Newborn Care: A Guide for Essential Practice. In: 3rd NM, Richard Casna, editors. Pregnancy, Childbirth, Postpartum and Newborn Care: A Guide for Essential Practice. Geneva: World Health Organization; 2015.

9. Vandenberg KA. Individualized developmental care for high-risk newborns in the NICU: a practice guideline. Early Hum Dev. 2007;83(7):433-42.
10. Liaw JJ, Yang L, Yuh YS, Yin T. Effects of tub bathing procedures on preterm infants' behavior. J Nurs Res. 2006;14(4):297-305.

11. Hall RW, Anand KJ. Pain management in newborns. Clin Perinatol. 2014;41(4):895-924.

12. Slater R, Cornelissen L, Fabrizi L, Patten D, Yoxen J, Worley A, et al. Oral sucrose as an analgesic drug for procedural pain in newborn infants: a randomised controlled trial. Lancet. 2010;376(9748):1225-32.

13. van Bel F, Mintzer JP. Correction: Monitoring cerebral oxygenation of the immature brain: a neuroprotective strategy? Pediatr Res. 2018;84(5): 786.

14. van Bel F, Lemmers P, Naulaers G. Monitoring neonatal regional cerebral oxygen saturation in clinical practice: value and pitfalls. Neonatology. 2008;94(4):237-44.

15. Slater R, Cantarella A, Gallella S, Worley A, Boyd S, Meek J, et al. Cortical pain responses in human infants. J Neurosci. 2006;26(14):3662-6.

16. Bornhovd K, Quante M, Glauche V, Bromm B, Weiller C, Buchel C. Painful stimuli evoke different stimulus-response functions in the amygdala, prefrontal, insula and somatosensory cortex: a singletrial fMRI study. Brain. 2002;125(Pt 6):1326-36.

17. Treede RD, Kenshalo DR, Gracely RH, Jones AK. The cortical representation of pain. Pain. 1999;79(2-3): 105-11.

18. Roue JM, Rioualen S, Gendras J, Misery L, Gouillou M, Sizun J. Multi-modal pain assessment: are nearinfrared spectroscopy, skin conductance, salivary cortisol, physiologic parameters, and Neonatal Facial Coding System interrelated during venepuncture in healthy, term neonates? J Pain Res. 2018;11:2257-67.

19. Verriotis M, Fabrizi L, Lee A, Cooper RJ, Fitzgerald M, Meek J. Mapping cortical responses to somatosensory stimuli in human infants with simultaneous near-infrared spectroscopy and eventrelated potential recording. eNeuro. 2016. https:// doi.org/10.1523/ENEURO.0026-16.2016.

20. Bembich S, Brovedani P, Cont G, Travan L, Grassi V, Demarini S. Pain activates a defined area of the somatosensory and motor cortex in newborn infants. Acta Paediatr. 2015;104(11):e530-3.

21. Gursul D, Hartley C, Slater R. Nociception and the neonatal brain. Semin Fetal Neonatal Med. 2019;24(4):101016. 
22. Ranger M, Johnston CC, Limperopoulos C, Rennick JE, du Plessis AJ. Cerebral near-infrared spectroscopy as a measure of nociceptive evoked activity in critically ill infants. Pain Res Manage. 2011;16(5):331-6.

23. Herold F, Wiegel P, Scholkmann F, Muller NG. Applications of functional near-infrared spectroscopy (fNIRS) neuroimaging in exercise(-)cognition science: a systematic methodology-focused review. J Clin Med. 2018. https://doi.org/10.3390/ jcm7120466.

24. Ozdemir H, Bilgen H, Gokulu G, Memisoglu A, Ozek E. Does repeated painful stimuli change cerebral near-infrared spectroscopy response in healthy, term, large for gestational age newborns? Clin J Pain. 2020;36(2):110-6.

25. Gomes Neto M, da Silva Lopes IA, Araujo A, Oliveira LS, Saquetto MB. The effect of facilitated tucking position during painful procedure in pain management of preterm infants in neonatal intensive care unit: a systematic review and meta-analysis. Eur J Pediatr. 2020;179(5):699-709.

26. Schepers RJ, Ringkamp M. Thermoreceptors and thermosensitive afferents. Neurosci Biobehav Rev. 2010;34(2):177-84.

27. Falcon M, Guendellman D, Stolberg A, Frenk H, Urca G. Development of thermal nociception in rats. Pain. 1996;67(1):203-8.

28. De Caro C, Cristiano C, Avagliano C, Bertamino A, Ostacolo C, Campiglia $\mathrm{P}$, et al. Characterization of new TRPM8 modulators in pain perception. Int J Mol Sci. 2019. https://doi.org/10.3390/ ijms20225544.

29. Fitzgerald M, Jennings E. The postnatal development of spinal sensory processing. Proc Natl Acad Sci USA. 1999;96(14):7719-22.

30. Hjerling-Leffler J, Alqatari M, Ernfors P, Koltzenburg M. Emergence of functional sensory subtypes as defined by transient receptor potential channel expression. J Neurosci. 2007;27(10):2435-43.

31. Liu B, Qin F. Functional control of cold- and menthol-sensitive TRPM8 ion channels by phosphatidylinositol 4,5-bisphosphate. J Neurosci. 2005;25(7):1674-81.
32. Takayama Y, Uta D, Furue H, Tominaga M. Painenhancing mechanism through interaction between TRPV1 and anoctamin 1 in sensory neurons. Proc Natl Acad Sci USA. 2015;112(16):5213-8.

33. Hassan IA, Wickramasinghe YA, Spencer SA. Effect of a change in global metabolic rate on peripheral oxygen consumption in neonates. Arch Dis Child Fetal Neonatal Ed. 2003;88(2):F143-6.

34. Hull D. Nutrition and temperature control in the newborn baby. Proc Nutr Soc. 1969;28(1):56-61.

35. Edraki M, Paran M, Montaseri S, Razavi Nejad M, Montaseri Z. Comparing the effects of swaddled and conventional bathing methods on body temperature and crying duration in premature infants: a randomized clinical trial. J Caring Sci. 2014;3(2): 83-91.

36. Caka SY, Gozen D. Effects of swaddled and traditional tub bathing methods on crying and physiological responses of newborns. J Spec Pediatr Nurs. 2018. https://doi.org/10.1111/jspn.12202.

37. Wong F, Yiallourou SR, Odoi A, Browne P, Walker AM, Horne RS. Cerebrovascular control is altered in healthy term infants when they sleep prone. Sleep. 2013;36(12):1911-8.

38. Tasdemir HI, Efe E. The effect of tub bathing and sponge bathing on neonatal comfort and physiological parameters in late preterm infants: A randomized controlled trial. Int J Nurs Stud. 2019;99: 103377.

39. Renesme L, Allen A, Audeoud F, Bouvard C, Brandicourt A, Casper C, et al. Recommendation for hygiene and topical in neonatology from the French Neonatal Society. Eur J Pediatr. 2019;178(10):1545-58.

40. Hyodo K, Dan I, Kyutoku Y, Suwabe K, Byun K, Ochi G, et al. The association between aerobic fitness and cognitive function in older men mediated by frontal lateralization. Neuroimage. 2016;15(125):291-300.

41. Fernandez D, Antolin-Rodriguez R. Bathing a premature infant in the intensive care unit: a systematic review. J Pediatr Nurs. 2018;42:e52-7. 